\title{
Stakeholder Conceptions of Later-Life Consumer Vulnerability in the Financial Services Industry: Beyond Financial Capability?
}

\begin{abstract}
When the newly constituted UK financial services regulator, the Financial Conduct Authority, was launched in 2013, it promised to adopt a new approach to its 'consumer protection' objectives. Part of this shift involved the articulation of a new conception of consumer vulnerability, going beyond narrow, individualistic, notions based on (limited) financial capability, to a broader conception which takes account of the connection between individual circumstances, situations and market factors in causing or exacerbating vulnerability. Drawing on new empirical research with later life financial services stakeholders and consumers, this article examines the extent to which this new regulatory philosophy is aligned with the realities of stakeholder perceptions and consumer experiences. We find that despite this regulatory shift, the stakeholders in our study tended to understand consumer vulnerability through a narrower lens, focusing predominantly on 'information vulnerability', or on whether or not the consumer 'knows what they are doing', with the consequent assumption that financial advice is adequate to ensure good consumer outcomes. This is at odds with our consumer study findings, which reveal a much wider range of sources of vulnerability. We therefore reflect on the implications of these findings for the development of the later-life financial services industry in ways that can more appropriately serve the needs of this consumer population.
\end{abstract}

\section{Keywords: vulnerability; ageing; consumer protection; financial regulation; equity release}

\section{(1) Introduction}

When the newly constituted UK financial services regulator, the Financial Conduct Authority, was launched in 2013, it promised to adopt a new approach to its 'consumer protection' objectives. Following a period of intense review and reflection in the wake of the global financial crisis, the Financial Conduct Authority's Approach to Regulation promised to 'be more outward-looking and engaged with consumers than the FSA has been... and better informed about their concerns and behaviour where this is relevant to regulatory action' 
(FSA, 2011a: [1.11]). Recognising that the pre-crisis approach to consumer protection was underpinned by (potentially flawed) assumptions about the nature, sources and extent of consumer vulnerability, the new approach has emphasised the importance of informing its regulatory framework with a more nuanced and realistic understanding of consumer vulnerabilities (FCA, 2015). In its 2015 Occasional Paper, Consumer Vulnerability, the FCA articulated a fresh conception of consumer vulnerability. Rejecting individualistic explanations that focus largely or solely on consumer characteristics such as limited cognitive ability or impaired capacity (Ringold, 1995; Smith and Cooper-Martin, 1997), this new framework acknowledged the interplay of individual circumstances, the situation or context of the transaction, and the part played by market or firm behaviour in amplifying consumer vulnerabilities in certain circumstances (FCA, 2015). This approach emphasises the complex nature and range of sources of consumer vulnerability, acknowledging the temporal (in the immediate situation), as well as persistent, nature of vulnerabilities (e.g. Cartwright, 2015; Consumer Affairs Victoria, 2004).

The FCA recognised that, in order to meet the real challenge of ensuring appropriate consumer protection in financial services, it would not be sufficient merely to articulate a finely nuanced definition; rather the success of the approach would depend on the degree to which this broader conception became embedded both in the culture of the regulator and in the practices of firms (FCA, 2015, p.19). This paper reflects on the process of embedding this new conception of vulnerability in the context of later life consumer financial services. Focusing on equity release transactions, our aim is to understand how financial services stakeholders conceive of later-life consumer vulnerability, in the context of the FCA's new approach, and the realities of the consumer experience. To do this, we draw on new empirical data from a qualitative 'stakeholder study' that explored the nature of consumer vulnerability with a range of actors operating in the equity release sector (product providers, advisers, lawyers, industry trade bodies and consumer organisations). Prompted by the initial findings of our stakeholder study, we have also conducted a fresh analysis of data from our earlier consumer study (70 consumers of equity release products), to compare stakeholder conceptions with the realities of the consumer experience, as well as with the FCA's new approach. In this analysis we draw upon Cartwright's (2015) 'taxonomy of vulnerability', which identified five (sometimes interconnected and overlapping) forms of consumer vulnerability: (1) information vulnerability, where some consumers may be particularly vulnerable to difficulties in obtaining and processing the information necessary to make 
informed financial decisions (including limited ability to use information seeking tools such as the internet); (2) pressure vulnerability, where decisions are made under pressure, whether applied by others or contextual pressures; (3) supply vulnerability, whereby the consumer has access to limited choices within the market; (4) redress vulnerability, whereby some consumers face greater difficulty in achieving redress and (5) impact vulnerability, where loss or harm disproportionately impacts on certain consumers. Cartwright's taxonomy seeks to align different types of market intervention to particularised vulnerabilities: for example, where the source of vulnerability is lack of information, this might be appropriately addressed through mandatory disclosure; where the vulnerability relates to processing complex information, standards governing the clear and transparent presentation of the information, or perhaps requiring individual advice to help consumers negotiate the information and understand their choices, might be an appropriate response. ${ }^{1}$

Our focus on older consumers of financial services, and specifically equity release consumers, is justified on a number of grounds. Firstly, in the context of ageing, neo-liberal, societies, where responsibility (and the associated risk) for retirement security is increasingly individualised, financial services are playing an increasingly central, and essential, role in older people's lives, particularly in the policy spheres of pensions, long-term care, and housing wealth decumulation (Price and Livsey, 2013), including through the use of commercial equity release products. Equity release products are a distinct form of home finance product targeted at older owners, allowing them to access some of the value of their homes without having to move or make repayments by instalment. Though the UK market remains small at just 2 per cent of the residential mortgage market, sales surpassed $£ 2$ bn for the first time in 2016 (ERC, 2017) and are expected to increase further still by the end of 2017. Furthermore, both the UK government and the industry have articulated high expectations for growth in this market, to "enable more people to use their assets to help pay for the cost of their social care, to adapt their homes, and to support their incomes' (House of Lords, 2013, p. 138). Meanwhile, the squeeze on other forms of retirement borrowing

\footnotetext{
${ }^{1}$ In previous analyses of data from our consumer study, we focused on the consumer experience of equity release transactions: for example, examining the extent to which the regulatory paradigm of information and professional financial and legal advice meets the needs (or not) of a differentiated consumer population (Fox O'Mahony and Overton, 2014); the impact of housing wealth decumulation through equity release on the meanings of the owned home (Fox O'Mahony and Overton, 2015); and the factors that influence later-life consumer attitudes to using housing equity to pay for care (Overton and Fox O'Mahony 2017). This article shifts the primary focus of analysis from the consumer experience to stakeholder conceptions of consumer experiences.
} 
(Overton and Fox O'Mahony, 2015) has left consumers approaching, and in, retirement with fewer options, and with the financial services regulator shifting from designating equity release products as a 'higher risk area' (FSA, 2008) to defining equity release consumers as a 'vulnerable population' (FSA, 2011b), there is a pressing, and growing, need, to ensure good consumer outcomes in these transactions.

Secondly, while consumers interacting in any market can experience some degree of vulnerability, the risks and challenges particular to financial services - such as the long-term nature of commitments, the potentially long term-impact of a sub-optimal product choice, and the complexity of products and information - mean that vulnerable consumers of financial services are more likely to suffer harm than the average (non-financial services) consumer. And, crucially, the FCA has recognised that detriment is particularly likely to occur when the product or service is essential to the needs of the consumer, rather than discretionary (FCA, 2015, p. 22).

Finally, there is a clear consensus across the government, the industry and the sector, that ensuring - and improving - the suitability and effectiveness of financial services for older people is a priority concern. The Occasional Paper, Ageing population and financial services (FCA, 2017a), which recognised the need for both the regulator and the financial services industry to better meet the needs of older people, was part of the FCA's 'Ageing Population' project. At the same time, the Council of Mortgage Lenders has commissioned research on retirement borrowing (CML 2015, 2016a, 2016b, 2017), which seeks to better understand older consumers' needs and behaviour, and the responsiveness of the lending and advice industry to these specific needs. In a preliminary study of older consumers' advice needs, the CML report (2017) acknowledged that older consumers' needs and preferences are not being met in full, and that better solutions will require changes to business models, products, regulation and advice services. This echoes the findings of previous research with older consumers that highlighted the limitations of the 'advice paradigm' - a dominant feature of the UK's regulatory approach to older consumers - in meeting the needs of a differentiated population of older consumers of financial services (Fox O'Mahony and Overton, 2014).

In 2016 (FCA, 2016), the Financial Conduct Authority also urged the industry to 'do more to support the UK's ageing population and ensure that consumers can access the financial products and services they need at every stage of their life'. This appeal to industry to lead 
the work of better aligning financial services targeted at older consumers to their needs was echoed in 2017, when the FCA highlighted areas of concern around product and service design, customer support, and the need for firms to continuously adapt and review their strategies. The FCA concluded that:

There is scope for financial services firms to do more. We have set out some ideas that we want firms to consider as part of how they Treat Customers Fairly. These are diverse challenges that firms need to address in ways that fit their business models. As such, we are not proposing rules or guidance at this stage. However, we may return to this and consult on changes to our rules or guidance in the future if we think this is needed. (FCA, 2017a, p.8),

Applying the approach adopted by the FCA under the Financial Services Act 2012, this requires a nuanced approach, grounded in a: '...commit[ment] to a better understanding of consumer behaviour, consumer needs and consumer experiences... and to building the consumer perspective into all its work...work[ing] with the grain of consumers' behaviour.' (FSA, 2011a: [4.10; 4.12])

This article therefore explores how stakeholder conceptions have shaped their understandings of 'consumer vulnerability' within the equity release market; their attitudes to FCA regulation - particularly to the role of regulation in achieving good outcomes for later-life consumers; and their views about the future direction of the industry. Evaluating these findings against the evolving regulatory narrative, and the realities of the consumer experience as reported in our consumer study findings, we reflect on the work that will be needed to enable the industry to respond to the FCA's call for self-regulation that echoes its commitment to working with the grain of consumers' behaviour. Finally, we consider the implications of effective alignment between industry stakeholder and regulatory conceptions of older consumers for the development of the later- life financial services industry in ways that can appropriately serve the needs of this consumer population. 


\section{(2) Financial Services Stakeholders, Vulnerability and Later-Life Consumers}

Stakeholder conceptions of consumer vulnerability are an important factor in consumer protection regimes, not only because of the FCA's general reliance on the recalibration of embedded norms to deliver its objectives, but also, specifically, in light of its current approach to later-life financial services. In its Occasional Paper on Ageing Population and Financial Services (FCA, 2017a), the FCA noted that: '[a]ll too often, products and services appear designed for an 'average' consumer who may not exist'; or that processes and policies are designed not around customer, but corporate need, with too few products effectively anticipating the needs of an ageing population. The FCA offered four reasons why older consumers may differ from other consumer groups; two of these related to situational or contextual vulnerabilities (financial needs and circumstances; likelihood of experiencing specific life events) while the other two were more directly linked to the ageing body (capacity and preferences; likelihood of experiencing changes in physical and mental health) (FCA, 2017a, p.16). Focusing specifically on home equity lending in later life, the FCA recognised barriers that may affect an older consumer's ability to research, identify or access a mortgage product that meets their needs (for example the opacity and complexity of lending criteria); limited appetite amongst some lenders for later-life lending (with possible causes being lenders forming judgements that these borrowers may pose increased regulatory or commercial risks); and potential barriers to innovation. Our previous research also noted consumer dissatisfaction with high interest rates, costly early repayment charges, and inflexible portability terms (Overton and Fox O’Mahony, 2015; Fox O’Mahony and Overton, 2014).

\footnotetext{
Although the FCA's three operational objectives (consumer protection, market integrity, competition), are together intended to 'promote good outcomes for consumers, through a differentiated and proportionate approach which takes into consideration the knowledge and financial sophistication of the various types of consumer...' (FSA, 2011a: [1.11]). in meeting this objective, financial services stakeholders, including the FCA, must have regard for a range of differentiating factors across the spectrum of retail financial services, from differing levels of product risk to variations in 'consumer risk' - their experience, expertise and expectations of different products, as well as different needs for information and advice
} 
In seeking to understand how specific markets work, the specific needs of consumer sub-populations, and how these interact with product risk within a sub-sector, the FCA looks to its stakeholders, including consumers (through the Financial Services Consumer Panel (FSCP)) and the markets, sub-sectors or industries themselves. Perhaps inevitably, the financial services industry has significant power to influence the regulator's understanding of sub-markets. The relatively closed categories of sector-specific stakeholders - particularly in small or highly specialised sub-sectors such as equity release - can create a risk of (innocent or not) shared cognitive or intellectual capture around an imperfect understanding of consumers, their needs and the nature and extent of 'appropriate' consumer protection. This is compounded when the industry voice speaks in alignment with the prevailing political ideology, and where the 'highly specialised' nature of the market makes it more difficult for the consumer voice to be heard - or even to articulate a credible and compelling challenge to a shared dominant discourse across industry and regulator.

One example of this 'regulatory capture' (Stigler, 1971) - manifest in the pervasive beliefs that were widely shared between the regulator and the financial services industry leading in to the global financial crisis - was the industry, government and regulator commitment to information disclosure and advice (to enable consumers to make informed rational choices in specific transactions) and consumer financial education and financial capability (to prepare customers to seek out, understand, and make good decisions based on information and advice) as effective consumer protection strategies. The dominance of the 'information paradigm' in financial services regulation was predicated on the belief that, across a consumer population with different preferences as to the balance between quality, safety and price, adequate information allows consumers to exercise choice in line with their preferences. The administrative costs of formulating and enforcing disclosure rules are also relatively low, compared to a standards regime, given that policy-makers are not required to determine optimal levels of loss abatement. Politically, the financial capability agenda is a 'pro-market' approach to consumer protection (Cartwright, 2004, p.62), geared towards improving consumers' abilities to make rational informed choices as 'self-responsible' citizens and focused on 'inside the (consumer's) head causes of market failure: on influencing consumer behaviour and strategic consumer choice; on increasing consumer literacy and financial capability; and on building consumer trust in financial services providers to offer products of an appropriate type and quality (Ennew \& Sekhon, 2007). In Cartwright's terms, it sought to address information vulnerability, over other sources of consumer vulnerability (pressure, supply, redress, impact). 
To date, government regulation of equity release has been broadly based on the 'information paradigm', supplemented by professional financial and legal advice. Lifetime mortgages were brought under the FSA's regulatory jurisdiction in 2004, and home reversions followed in 2007. The initial approach to regulating these products (through information disclosure, 'key facts' statements, and specific health warnings) was essentially an enhanced version of the conventional mortgage regime. Additional sections of the Mortgages and Home Finance Conduct of Business Sourcebook relating to equity release (MCOB 8 and 9) set out advising and selling standards, product disclosure requirements, and good practice guidelines, including standardized content, order, and form for illustrations, start of contract, and after-sales information. These were largely based on MCOB 5 for standard mortgages, adapted to reflect the distinctive features of the products. In addition, the 'risk statement' for lifetime mortgages included a strong steer towards professional financial advice (MCOB 3.6.13), and following the Mortgage Market Review (FSA, 2011b) - which designated equity-release consumers as 'vulnerable' ([5.77]), extrapolating from this questionable conclusion that they will 'benefit from advice more than others' ([5.78], see Fox O’Mahony \& Overton, 2014) - financial advice is now mandatory unless the consumer is exempt. This emphasis on information and advice tended to focus attention on the putative complexity and high-risk nature of equity release products, with less emphasis on the circumstances in which equity release consumers take out products.

The FSA's (pre-crisis) approach to regulation was aligned with the UK Government's political commitment, expressed by HM Treasury (2000), to create 'knowledgeable consumers' who 'with the right information...can take responsibility for their own financial well-being, shop around and exert the pressures on suppliers which drive a competitive and innovative market' (Executive Summary, [50]). Even before the financial crisis, this approach was widely criticised for exposing consumers - particularly those with lower 'financial capability' - to the significant burden of assimilating complex information and making decisions in a context that they are not well placed to negotiate. And, noting that the idea of 'consumer vulnerability' is conceptually complex, politically predicated and emotionally loaded, there was also evidence to indicate that consumer protection strategies based on a combination of information/advice and increasing financial literacy/capability offered least benefit to those who needed it most. Wilhelmsson (1997, p.224) described 'measures based on the information paradigm [as liable to] reproduce and even strengthen existing social injustice'; while Howells (2005, p.357) described consumer protection based in the information paradigm as 'protection for the middle classes', on the basis that 'vulnerable 
consumers' are less well-placed to manage their own risks based on information, and often have little choice in financial transactions due to contextual pressures necessitating the transaction, and to the limited options available to them in the market. In 1999, the Office of Fair Trading recognised that "there are limits to the information which consumers can assimilate, that these limits will vary between individuals and that just providing more information is not necessarily the answer to solving consumers' problems' (OFT, 1999): [700]). The OFT recommended that, rather than seeking to educate vulnerable consumers about complex products, providers should focus on simplifying the products on offer.

Following the Mortgage Market Review, the Financial Services Authority shifted from designating equity release products as a 'higher risk area' (FSA, 2008) to defining equity release consumers as a 'vulnerable population' (FSA, 2011b). The designation of any consumer population as 'vulnerable' and the identification and delivery of appropriate responses to consumer need are potentially fraught for industry stakeholders. As the FCA acknowledged in its 2017 Occasional Paper, '[g]eneralised approaches to dealing with older consumers may stereotype, patronise or offend, [and t]his can be challenging for firms operating at scale.' Nevertheless, the FCA has been working to expand its own regulatory tool-kit - beyond the (pre-GFC) information and advice paradigm - endeavouring to formulate more responsive solutions for priority and high-risk sectors, such as short-term, high-cost credit (FCA, 2014). As the regulatory landscape opens to strategies such as product design regulation, regulation of terms and conditions, and price-capping, there are important questions to consider about the capacity of those sectors which are encouraged to 'selfregulate' in response to identified concerns, to keep pace with the FCA's broadening approach, and to adjust the assumptions that the previous regulatory mind-set embedded about consumer vulnerability.

\section{(3) Methodology}

This article draws on analysis from two qualitative studies. The first study consisted of semistructured, in-depth interviews with fourteen equity release stakeholders ('stakeholder study'), carried out in 2014. Our primary aim in this study was to explore financial services industry stakeholder views about later-life consumer vulnerability. We were particularly keen to explore their perceptions of the equity release consumer population, including the reasons why people take out equity release; the characteristics and circumstances of the 'typical' consumer; how they have seen, and anticipate, changes in the circumstances, needs and 
objectives of the equity release consumer, and how they evaluate their consumers in terms of vulnerability and financial capability. We also probed on what stakeholders understand 'vulnerability' to mean in relation to consumers, which we mapped against Cartwright's taxonomy. Finally, we asked stakeholders a range of questions about the aims, approaches, benefits and costs of financial services regulation in this sector of the market, the role of information and advice, and the market more generally. To ensure that a wide range of views and experiences were represented, our stakeholder sample comprised individuals from tied and independent financial advisers, providers, consumer organisations, charities and law firms involved in equity release (Table 1 illustrates the stakeholder sample by sector). We did not set out to generalise findings across the stakeholder population; rather we intended to shed light on key equity release issues from a range of professional perspectives. The views of participants are theirs alone, and not necessarily those of the organisation/company/sector they are associated with.

Table 1 Stakeholder sample by sector

\begin{tabular}{|l|l|}
\hline ID & Role/sector \\
\hline S01 & Later Life Adviser /Consumer Organisation, Third Sector \\
\hline S02 & ER Provider, Private Sector \\
\hline S03 & ER Consultant, Private Sector \\
\hline S04 & Solicitor, ER Legal Firm, Private Sector \\
\hline S05 & Independent Financial Adviser (IFA) \\
\hline S06 & ERC/Industry Trade Body \\
\hline S07 & Provider, Private Sector \\
\hline S08 & ER Specialist IFA and consultant \\
\hline S09 & Lawyer, Legal Firm with ER specialism \\
\hline S10 & ER Adviser, Third Sector \\
\hline S11 & Provider, Private Sector \\
\hline S12 & Consumer Organisation, Third Sector \\
\hline S13 & ER specialist IFA, \\
\hline S14 & Provider, Private Sector \\
\hline
\end{tabular}

The stakeholder interviews took place in 2014, mostly over the phone. They ranged from 36 to 76 minutes in duration, with the average being 56 minutes. Each interview was digitally recorded, with prior permission, and fully transcribed. Individual identities have been anonymised. Our stakeholder study followed an earlier set of qualitative, semi-structured, interviews with 70 equity release consumers, conducted in 2013 ('consumer study'), which addressed the same key themes from the perspective of the consumers' own experiences of transacting in this market (Overton and Fox O'Mahony, 2014). This enabled us to analyse the findings from our stakeholder study against the backdrop of our consumer study findings. The recruitment of participants was facilitated by a previous equity release study (Overton, 
2010). We wrote to all those who had agreed to take part in future equity release research (251 people), asking if they would like to be part of this project. Of this sample, 70 opted to take part in the 2013 study. Using participants' self-reported financial situation before taking out equity release (captured in previous study), the sample was divided into higher and lower financial wellbeing categories. Those placed in the lower category had stated that before taking out their equity release plan they were 'finding it very difficult to get by', 'finding it quite difficult' or 'just about getting by'; while those deemed to have higher levels of financial wellbeing had reported that they were either 'doing alright' or 'living comfortably' (see Table 2 for sample characteristics). Again, all interviews were recorded, with the prior permission from participants, and transcribed. Participants have been given pseudonyms and the quotations used do not contain identifying information. We analysed both the consumer and stakeholder datasets thematically, using the framework analysis method (Spencer et al, 2003).

\begin{tabular}{l|l}
\hline & Number \\
\hline $\begin{array}{l}\text { Self-reported financial } \\
\text { situation before entering } \\
\text { into equity release }\end{array}$ & \\
Lower financial well-being & 34 \\
Higher financial well-being & 36 \\
& \\
Household type & \\
Couples & 30 \\
Single female & 22 \\
Single male & 18 \\
& \\
Age & \\
$66-70$ & 5 \\
$71-75$ & 16 \\
$76-80$ & 20 \\
$81-85$ & 24 \\
$85+$ & 5 \\
&
\end{tabular}




\section{(4) Findings}

Conceptions of consumer vulnerability: the stakeholder view

Explanatory frameworks for 'consumer vulnerability' range from individualistic explanations, that focus largely or solely on consumer characteristics (e.g. Ringold, 1995; Smith and Cooper-Martin, 1997), to more complex accounts which recognise a variety of sources of vulnerability, ranging across the interaction of market, product, and supply characteristics and personal attributes and circumstances (e.g. Cartwright, 2015; Consumer Affairs Victoria, 2004; HM Treasury, 2008). Some have challenged the usefulness of the very concept of vulnerability, preferring to describe certain consumers as 'at a disadvantage' (George and Lennard, 2007, p.56), to avoid the potentially divisive and stigmatising effect of labelling certain consumers 'vulnerable' (Stearn, 2012).

We asked all stakeholders whether, and if so why and how, they conceived of (some) equity release consumers as vulnerable. While the Cartwright taxonomy suggested a variety of frames through which to conceive of consumer vulnerability, participants in our stakeholder study generally located the idea of consumer vulnerability in whether or not the consumer 'knows what they are doing' at the point of sale. On this measure, the majority of stakeholders viewed equity release consumers as generally capable and well-informed. For example, reflecting on whether, in general terms, he viewed equity release consumers as 'vulnerable', Stakeholder 06 said: ...these are not naïve people, they've been round the block a few times and know a thing or two about money and finance ( Equity Release Industry Trade Body). Stakeholders did not assume a direct correlation between age and vulnerability, suggesting instead that vulnerability depended on whether the individual consumer knew what they were doing or not, and that age does not necessarily determine the financial capability of the consumer:

The image that you sometimes see in the press - of being elderly and vulnerable and not knowing what they were doing - that is not your typical customer. They're very, very aware of what they're doing and quite sophisticated... There's an immediate assumption that because somebody is old then they're automatically vulnerable. They're not automatically vulnerable and they do know what they're doing... (Stakeholder 11) 
Other stakeholders cited examples of cases from their experience in retail financial services which demonstrated that financial 'savvy' - or naïvity - does not correlate with age. For example, Stakeholder 13 said:

I think the prospect of them being vulnerable does increase with age, naturally, it's bound to. But I've met financially naive people when I was advising on ordinary mortgages and pensions 20-odd years ago, who were in their 20s and 30s. They're not vulnerable by virtue of age 'cause each client is different ... and I can see an 85year old, and the 85-year-old may be more savvy than a 65-year old

Similarly, Stakeholder 05 said: 'I've got a couple of 75-year-old clients who are sharp as a button, make the right calls...' Describing one client, he said: 'He's of an age and, by nomination of age-only, who is a 'vulnerable client'. But he's extremely switched on.'

Another stakeholder was critical of labels like 'vulnerability' on the grounds that they tend to 'lump people together' under broad assumptions. She described a younger, professionally qualified, client who did not necessarily 'get it', in the sense of being financially capable or 'knowing what he was doing'.

I always think that vulnerability's a very bizarre thing in financial services. They lump all older people together, but, in fact... I can talk to a 45-year-old GP that lives very near to me. I find him very vulnerable in financial services; he doesn't get any of it, and yet he'd be regarded, as, you know, quite savvy (Stakeholder 01).

Only a minority of stakeholders linked vulnerability - in the sense of impaired capacity or reduced capability - to advancing old age (75 and older). One stakeholder associated vulnerability with lack of experience in financial transactions:

A vulnerable client is maybe a widowed person who hasn't been used to making those financial decisions in their household... I think people who are not particularly commercially minded or haven't been during their working lives...I think they're potentially vulnerable as well. (Stakeholder 04)

More typically, stakeholders emphasised the differentiation of consumer populations, describing the adoption of a 'blanket approach to any sector of society or any age group or any product' as an 'outdated viewpoint' (Stakeholder 08). Stakeholder 08 illustrated this with reference to his experience of advising older clients: I've sat with incredibly astute financially aware people, who were in their 80 s... So I think it's dangerous to make assumptions that everybody is vulnerable. 
Some participants were uneasy about categorising equity release consumers as vulnerable, because they perceived this as a label which is linked to negative connotations about lack of financial capability or capacity. For example, Stakeholder 02 said:

I think many of the customers we deal with would be insulted to be told they're vulnerable...probably as you get to the older stages, yes, there can be more vulnerability, but I think if you ask somebody who's 60, 65, do they see themselves as old and vulnerable, I think quite a few of those would be insulted

It has been widely recognised that the intersections between ageing and vulnerability raise politically and emotionally loaded connotations. In the current political landscape, the implication that later-life consumers are, by reason of age, less able to participate in market transactions also implies that older consumers are less capable of 'performing' as active and responsible consumers, managing accumulated resources to provide for themselves in later life (Leonard, 1997, pp.53-54). Legal discourse has long struggled with the tensions between appropriate protection and negative labelling, as well as the perceived risk that 'special treatment' of a particular group of consumers might adversely affect the willingness of creditors to enter into contract with them, inhibiting transactions and - counterproductively making it more difficult for protected consumers to access financial services. Indeed, where access to 'special' protection requires a construction of the vulnerable consumer as weak or disempowered, with echoes of paternalism, stigma, and negative connotations for personal dignity, where this denies the older person the opportunity to make binding choices, and so appears to undermine their 'autonomy', this can be viewed as 'too high a price to pay' for protection. This focus on (lack of) financial capability invokes an individualised, agencybased idea of vulnerability. Narrow conceptions of vulnerability, anchored in whether the consumer 'knows what they are doing', leave little scope for recognition, and mitigation, of the more complex account of vulnerability within Cartwright's taxonomy, the FCA's current definition, or, indeed, the lived reality of consumer experience.

While the 'individualised' conception of consumer vulnerability was most frequently articulated by our stakeholder sample, another, less commonly identified source of vulnerability referred to by our participants was 'pressure vulnerability', linked to family or carers. This was captured in the following quotes:

For me it's usually the older client, particularly where you see an instruction coming in from a son or daughter, or a friend or something like that. That immediately rings 
alarm bells and you think, 'What's going on here? What are the reasons behind it?' (Stakeholder 04)

I think the greatest vulnerability my borrowers potentially have is exposure to either inappropriate behaviour on the part of family members, or inappropriate behaviour on the part of people that they perceive as someone they should trust, or they do trust, potentially, as a result of being lonely. (Stakeholder 14)

This line of thinking was also reflected in Stakeholder 10's conception of vulnerability as 'being taken advantage of'. He underlined the importance of good advice as the appropriate response to this type of pressure vulnerability:

vulnerability for me is probably if the wrong person tries to help them they'll take advantage of what they have... vulnerability is only ever really a risk if you combine someone who's vulnerable with someone who's dodgy, if you combine someone who's vulnerable with a good advisor who's there to look after you, you don't really have to worry about the vulnerability because they'll look after you

Notably, only one of our stakeholder participants - who worked for a third sector consumer organisation - suggested that the socio-economic situation of equity release consumers might render them vulnerable. Stakeholder 12 suggested that:

pretty much anyone going for an equity release scheme is vulnerable, in so far as they're looking to borrow money...These are not rich people, who are investing money and have a lot of back-up, so the very reason they're going for equity release must mean that they don't have a lot of access to a level of money, otherwise they wouldn't do it. So from that point of view they're in a vulnerable position.

This stakeholder was also concerned that the nature of the products, longer-term implications of certain terms and conditions, and the need for consumers to think through future needs makes equity release a high-risk transaction: 'because there are so many pitfalls...' They went on to explain this idea of consumer vulnerability in terms of 'product risk', recognising that the language of vulnerability carried different meanings in this context: 'So it's not maybe vulnerable as you would often think of the word. These are not necessarily frail, elderly people living alone...' This resonates with what Cartwright terms 'impact vulnerability; the stakeholder's view was that advisers must therefore explain to consumers the complex array of future possibilities that might be determined by their transactional decision:

They need to be taken through all the bad things that can happen. They need somebody to sit with them and say, actually, if you borrow this amount of money, do 
you realise that in ten years' time it will be double that? You're saying now that you don't want to move. What if one of you has passed away and the other one did want to move nearer to your daughter or your son, do you realise that actually you might have to repay all of this money? To get out of it you might also have to pay penalty costs of this.

When we asked this participant to reflect on how this kind of vulnerability can be ameliorated, their response drew back to 'information and advice', underlining the importance of good advice to ensure that consumers are 'thinking this through'. This stakeholder, while recognising impact vulnerability, did not consider whether the nature of the products and their (in)flexibility to adapt to unknowable future eventualities should or could become the focus of consumer protection strategies.

The pre-eminent importance of professional advice - to effectively enable consumers to think ahead - was mentioned by several stakeholders: the main concern is to get the right advice that's forward thinking, forward looking, and most people don't have that vision, most people struggle to plan the money for a year's time, let alone the next ten, twenty five, thirty years' (Stakeholder 08). It is interesting to note that, rather than suggesting that this is a particular vulnerability for older consumers, Stakeholder 08 recognised that 'most people struggle to plan'. From this perspective, the risk of poor financial decisions is arguably not located in the individual (flawed) decision-maker, or with later-life consumers more widely; rather this participant was recognising the inherent difficulties, across the consumer population, of planning ahead to ensure the accumulation, management and timely decumulation of resources, as required by the financialised consumer society. Other stakeholders - who also identified 'product risk' as a justification for the FCA's mandatory financial advice requirement - echoed this perspective, when they articulated consumer risk in equity release transactions, not as an indicator of low financial capability amongst older people, but as a function of the high level of financial capability required for equity release decision-making, to be able to understand and choose between complex product features:

Some of the features of the products that are out there... the way that, for example, early redemption charges are calculated, on a lot of contracts out there, is complicated... [and] understanding the concept of roll-up interest and compound interest, you know. We, sadly, live in a nation where doing basic percentages is not the norm, is not easy. So, from a financial capability perspective, understanding the concept of equity release, it does need proper explanation (Stakeholder 14) 
These stakeholders recognised the high burden on older consumers to achieve high-levels of financial capability in the new retirement landscape of self-provision through engagement with the financial services market.

The stakeholder participants in our study typically conceived of 'vulnerability' in terms of 'labelling' older consumers as impaired, or lacking in financial capability; and seeing 'vulnerability' through this lens, they did not support the FCA's designation of equity release consumers as a 'vulnerable population' (FSA, 2011b: [5.77]). Indeed, our findings reveal a stronger alignment between stakeholder conceptions and the earlier regulatory conception of vulnerability as product-based risk in equity release transactions. The FSA's decision to designate lifetime mortgages as a 'higher risk area' within the Mortgage Effectiveness Review (FSA, 2008), was prompted by a concern about the risk of consumer detriment (FSA, 2007), but did not define the consumer population. Indeed, the survey concluded that the lifetime mortgage market 'works well for most customers most of the time' (FSA, 2008, p. 2).

Our stakeholder participants shied away from the language of 'vulnerability' because, in their terms, it implied a generalised lack of capability amongst the older population; yet, their observations about the difficulties involved in thinking ahead and long-term financial planning aligned with the very concerns that underpinned the FCA's new designation of equity release consumers as a 'vulnerable' population. The reasoning behind applying the label of 'vulnerable consumers' to equity release in the Mortgage Market Review (FSA, 2011b) was that it is a higher-risk product ([5.77], not because the consumer population were conceived as higher-risk consumers, per se ([5.86]). When the Review went on to state, in more general terms, that 'in the mortgage market there are consumers who are potentially more vulnerable and who would benefit from advice more than others.' ([5.78]), this was still premised on their assessment that the products were higher risk - and so the likelihood and impact of harm was greater - not on any inherent lack of capability among the older consumer population. Indeed, in explaining why the products were considered 'higher-risk', the FSA's analysis echoed the issues raised by some stakeholders about the difficulties of planning for the future and choosing financial products in an increasingly complex financial environment. For example, the Mortgage Market Review raised concerns about whether consumers releasing equity 'fully appreciate the wider implications of doing so, such as the impact on their tax position or their eligibility for State benefits' ([5.81]). This runs counter to the belief 
expressed by some stakeholders in our study that the FCA has adopted a generalised view that equity release consumers are vulnerable because of a lack of financial capability:

one of the bug bears we have with the FCA is...that they assume all our customers are vulnerable which is certainly far from the case in my experience...these are not naïve people, they've been round the block a few times and know a thing or two about money and finance (Stakeholder 06); or because of their age per se (Stakeholder 07).

Although stakeholders consistently did not recognise this, the issues that concerned them aligned with the FSA/FCA position. For both, however, this shared underpinning view mandated strong support for professional financial advice as the most appropriate ameliorating measure to help consumers negotiate the challenges and complexities of the new retirement landscape.

Changing contexts of equity release transactions - implications for consumer vulnerability

The FSA's 2008 Mortgage Effectiveness Review concluded that the lifetime mortgage market 'works well for most customers most of the time'; that lifetime mortgage consumers generally shopped around (doing this for themselves rather than relying on brokers); and that, while consumers generally (believed they) had a good understanding of the risks and features of the mortgages they had taken out, this was based on their own extensive personal research into the products, over a long period of time, weighing up the benefits and disadvantages of products against the alternatives, and discussing the decision with family members (FSA, 2008). The Review's qualitative findings also noted, however, that the amount of time taken to make the decision depended on the urgency with which the funds were needed; and that consumers tended to be hyperbolic discounters, placing greater emphasis on the short-term costs than the long-term suitability and value of the product (FSA, 2008, p.34). The role of financial advice in equity release decision-making, relative to other contextual factors, was a key focus of our consumer study (Fox O’Mahony and Overton, 2014). Participants were purposively sampled according to socio-economic circumstances at the time of the transaction, to enable us to explore the decision-making process, including the role and relevance of financial advice, across the differentiated consumer population. These findings indicated that, while financial advice was viewed as worthwhile and helpful by many consumers, it was most effective for those (predominately non-marginal/better-off) 
consumers who were most prepared to receive advice, who had already researched the options and who knew what questions to ask. We concluded that while reliance on financial advice as the principal vehicle for consumer protection may meet the needs of some consumers, for others, particularly more vulnerable consumers, additional measures may be necessary to enhance the effectiveness of the advice process, and so achieve an appropriate level of consumer protection. Such measures might, for example, reflect the importance for advisers to be sensitive to the needs and circumstances of the consumer not only in the present but into the future; the importance of the relationship between the consumer and the adviser, and the role of 'soft-skills' training in supporting a positive relationship in which the consumer feels able to ask questions. An awareness of the consumer's existing knowledge and understanding, with implications for their ability to ask questions, was also an important factor in achieving good outcomes for equity release consumers (Fox O’Mahony and Overton, 2014).

In the stakeholder study, we asked participants - drawing on their professional expertise and experience - to reflect on why people take out equity release plans, what they consider to be the characteristics of a 'typical' consumer, and whether they had observed, or anticipated, any changes in the equity release population. Across the sample, three reasons for releasing equity were consistently offered: (1) to enhance lifestyle after retirement, (2) to pay for home improvements, and (3) to meet pressing financial needs. All stakeholders talked about the use of equity release to improve lifestyles in later life, often because people had higher expectations in retirement than they could afford to support through pensions or savings. The consumers that these stakeholders had in mind as 'typical' were not in dire straits, but 'not particularly well catered for in their retirement' (Stakeholder 01). Similarly, when stakeholders talked about home improvements, they indicated that this covered a spectrum, from 'putting in a hot tub or something...[to] the kind of adaptations that you used to get ...local government grants for but you don't anymore and which allow people to stay in their homes longer as they get frailer.' (Stakeholder 06)

Many of our stakeholders identified a marked shift in the equity release market in recent years, away from lifestyle uses to pressing financial needs. For example, Stakeholder 11 observed that:

back in 2006-07 when house prices were growing and everyone was quite buoyant there was a lot more use for luxuries rather than necessities. More people were using 
it...to go on holiday and to buy a new car and all those sorts of things. Now we're finding more and more that it's geared towards essentials that they need.

Participants suggested that this shift was linked to the economic climate - suggesting that ' $I$ suspect that it will go back to that [luxuries] again as the economy recovers'. Several other stakeholders remarked on a noticeable shift towards debt consolidation: Stakeholder 14 suggested that: $[\mathrm{m}]$ ore commonly, from our perspective, it appears to be people who've actually racked up credit card bills, as opposed to mortgage debt; while Stakeholder 02 agreed that: 'it definitely has swung back to paying off debt, and I think that's the recession...'.

The perception of a trend towards the use of equity release for essential, rather than lifestyle, purposes, has been supported by recent market data: 23 per cent of consumers used equity release in 2017 to repay mortgage debt - up from 17 per cent in 2010; and there was a marked increase in those utilising the funds to repay unsecured debt, accounting for 30 per cent of consumers releasing equity in 2017 (Key Retirement Solutions, 2017). This was also reflected in our consumer study findings, where a significant minority of participants had used equity release to service mortgage and non-mortgage debt. Our findings revealed that these consumers, who were making the decision under pressure, typically spent relatively little time shopping around, weighing up the benefits and disadvantages of equity release against the alternatives, and discussing the decision with family members. Confusion around the details and operation of the plan were also more apparent among these participants. For example, Ken, who was in the lower financial well-being category and took out equity release to ease financial difficulties, said:

We had to go the solicitor to get the papers put in order and signed and sealed. At that particular time I hadn't realised that I was selling all the house...I thought I was only selling half the house...it wasn't until I'd come home and started reading through it that...the agreement is between my wife, myself and the company. And the rest of the family have no say in it...like when we die... and you read on a bit further and it says that anything that needs repairing or replacing will be done and paid for out of our estate (Ken, age 80).

Ken had tried to research the options before seeing an adviser by going to the library to use the computer, but did not find the information easy to access or process. When asked if there was any additional information or advice he would have found helpful, Ken said 'it would be 
good if information was more readily available and not just online'. Similarly, Betty, who used equity release because she had no other way of raising the money needed to pay off her credit card debts and support her everyday living expenses, said: 'I can't say I understood all the intricacies, I understood what I was going to get. That was the main thing for me' (Betty, age 86, lower financial well-being). When we interviewed Betty, several years after taking out the plan, her physical health had deteriorated and, unable to move house due to the small amount of equity remaining in her property, she said that she felt 'trapped' in a house that was no longer suitable for her. And Dorothy, who was 80 years old when we interviewed her, had taken out a lifetime mortgage with her husband to repay an unsecured loan that was causing them considerable anxiety. Dorothy said that although she thought it was the best option at the time, and couldn't really see another way of raising the money, looking back she felt that the adviser may have been 'a bit pushy' and now regrets her decision. These findings from our consumer study highlighted the overlapping and interconnected nature of different sources of vulnerability, and call into question the widely-held stakeholder assumption that advice is the solution to good consumer outcomes, particularly for consumers who are transacting under financial pressure.

The FSA's Mortgage Market Review designated the consumers who are borrowing to consolidate existing debt as the 'highest-risk' consumers (FSA, 2011b). While the stakeholders in our study recognised the market shift towards needs-based equity release, this did not disrupt their perceptions of consumer vulnerability. Indeed, many of the stakeholders who specifically highlighted the shift to needs-based borrowing also articulated, in other parts of the interview, their perceptions of the 'typical' consumer:

somebody who's quite financially astute, has discussed it through with their potential beneficiaries already and has done a degree of research themselves as well as then receiving advice and waiting for another period, before eventually deciding yes, it's the right product and right time, right solution, for them (Stakeholder 05)

This was echoed by Stakeholder 04 who said:

They [consumers] have usually done quite a lot of research themselves before they get to the point of committing to even the valuation, getting to having an offer issued. Our experience generally says that they've been thinking about it for a couple of years, usually before they take the plunge.

Our consumer study findings suggest that this perception fails to take sufficient account of the 'pressure vulnerability' (Cartwright, 2015) linked to transacting under financial difficulty, 
and the potential this has to render consumers susceptible to disadvantageous business dealings (Best, 1981). Our consumer study found that in a context of pressing needs, consumers necessarily focused on the immediate value and benefits of the transaction perhaps at the expense of consideration for long term suitability. The reported effect for some consumers in our study was that they were not in a position to appreciate the finer details of the plan, or warnings about long terms risks and costs, even if these were fully and clearly explained.

Limited recognition among our stakeholder sample that adverse financial circumstances may specifically cause 'vulnerability' - by negatively impacting consumers' ability to take time to research the options, digest the information and make fully informed decisions, as well as to manage the longer-term impact of equity release - is therefore at odds with the realities of the consumer experience. Furthermore, while all stakeholders recognised the diversity amongst the equity release consumer population, commenting on the considerable diversity of circumstances and reasons for doing it, they tended not to associate such heterogeneity with the need for, or even desirability of, a differentiated approach to consumer protection. The predominant assumption that the source of vulnerability in equity release transactions lies in financial capability, or whether the consumer 'knows what they are doing', underscored the widespread, continued, support for a one size-fits-all approach based on information and advice. While the effects of contextual pressure in consumer transactions that are geared towards meeting pressing financial need undermines the effectiveness of advice in overcoming vulnerability, the stakeholders in our study tended to understand 'consumer vulnerability' through a narrower lens, focusing on information vulnerability and (where they considered 'pressure vulnerability') seeing pressure only in the sense of third party pressure/potential financial abuse and not as situational or contextual vulnerabilities linked to the pressure of financial circumstances. This narrow conception led all our stakeholder participants to assume that (good) advice offered an adequate - and, indeed, the only conceivable - safeguard to ensuring good consumer outcomes. The prospect that, in certain circumstances, even 'good' advice may not compensate for or ameliorate 'pressure-ofcircumstances' vulnerability was not considered. Stakeholders did not think outside the 'advice paradigm' to imagine other ways of regulating more responsively to meet the needs of consumers under contextual pressure. 
Stakeholder views on the role of regulation

Finally, we asked stakeholders what they understood to be the purpose of financial services regulation. Responses to this section of the interview revealed the effects of stakeholders' narrow conception of vulnerability in limiting the scope of their ambition for the role of regulation. Respondents typically focused on the role of regulation in supporting good consumer outcomes through the advice framework:

What regulation, I believe, should be seeking to achieve, is better outcomes for clients through full information disclosures and everything else (Stakeholder 05)

To protect the client, ultimately, at the end of the day. It's to make sure that the client is getting the best advice (Stakeholder 13)

Reflecting on why he considered advice to be essential in helping consumers to make informed decisions about equity release, Stakeholder 03 claimed that it was because:

I don't believe that most consumers read half of what they're sent on a financial product because the regulation of it is far too onerous...The bumpf that gets sent out to consumers when they reach retirement is just ridiculous. And that's not a provider issue, that's by and large a regulatory requirement...I'm not saying what goes out is wrong, because I think there's a lot of really good stuff in there, what I'm saying is people don't read it, so therefore it's irrelevant (Stakeholder 03)

The specific commitment to mandatory advice as the mechanism for enabling consumer protection strategies based on information to be successful responds to the concern particularly salient in respect of older consumers (Fox O'Mahony, 2012, pp. 171-2) - that more information does not necessarily improve decision-making. The advice requirement seeks to enable consumers to use information more effectively. Yet, while the stakeholders in our sample subscribed to the received wisdom that information without advice is inadequate, there was little recognition that for advice to be successful (in providing adequate protection) consumers also have to be able to use that advice effectively - that is, to have the capacity to interpret it, and be willing and able - in the context of their decision-making - to incorporate it in their decision-making process. As outlined above, our consumer findings reveal that for those who are most vulnerable, particularly those who experience contextualised pressure related to pressing financial need, advice is not always sufficient to support good outcomes compared, for example, to flexible terms that better enable older consumers to navigate the realities of changing needs and circumstances throughout their later life. 
One participant, who agreed that '[t]he regulation needs to be about the advice you give' also added 'I would also like to see some regulation in terms of products, so that there are not unfair terms in there, but the market could probably lead that.' (Stakeholder 12). The suggestion that the responsibility for developing fair, safe and suitable product terms lies with the market (rather than the regulator) is perhaps unsurprising against the backdrop of a regulatory framework that was designed around the 'information and advice' paradigm. Commenting on the process of designing the regulatory framework for equity release, one stakeholder observed that:

I think they (FSA)...inherited a regime that they didn't fully understand... so what they did initially was adopt the rules, the voluntary rules, under the mortgage compliance board conduct that had been running for five or six years, so they didn't invent anything themselves, they just thought well okay, we'll just follow that, it seems to have worked. And it was only by tinkering at the edges over the years that they changed things ever so slightly... (Stakeholder 08)

Indeed, even within the scope of a shared industry/regulatory commitment to advice as the preferred mechanism for consumer protection, equity release was exempted from the provisions of the Retail Distribution Review (RDR). The RDR was implemented as part of the FCA's strategy to improve consumer protection by making the retail investment market more transparent, efficient and attractive to consumers (Price and Livsey, 2013), and required that, from 2013, regulated independent financial advisers must declare their charges and can no longer take commission on products. Since the RDR was not applied to the equity release sector, these transactions remain exempt from its protection. This was also raised by participant S12, who expressed a strong view that advisers should operate on a fee, rather than commission, basis, so ensuring there is no incentive for advisers to make inappropriate or poorly judged sales:

The priority for the FCA is the regulation of that advice, and where they could have a huge impact is by sweeping equity release into RDR. So they remove...the sales incentives and the remuneration in that way. That could have a transforming effect on the whole advice thing, because then you will get true professionals who are comfortable enough to work on a fee basis (Stakeholder 12)

A small number of stakeholders also suggested that advisers should be trained to a higher standard, although there was also some concern that this would discourage new advisers from entering the sector and encourage others to cease advising in this area. 
Stakeholders perceived the equity release market to be tightly regulated, compared to other areas of consumer financial services, and indicated that that there was little more the sector or regulator could do to offer greater protection in support of better consumer outcomes:

I think we are regulated to the point where we're quite strait-jacketed in terms of the way that the sector operates and what that means, even if consumers don't know it or appreciate it, is that actually it's probably the safest product in the financial market now (Stakeholder 02)

It's difficult to think what more we could do to protect people, we say they've got a no negative equity guarantee, security of tenure, they should get independent financial advice, independent solicitor sign off, you know short of saying they should talk to a priest or something it's difficult to see what more we could do so some might say that's overkill. But we're often faced with the argument in the same breath that it's an expensive product but at the same time it should have even more protection, now I don't know what those extra protections would be but all the existing ones come at a price (Stakeholder 06)

I can't think of any better way of doing it. I'm not convinced with the assertion that you can't make people understand this (Stakeholder 11)

At the same time, a number of stakeholders questioned the usefulness of the existing statutory regime in helping consumers to make better decisions. This was framed by the assumption that regulation is (only) geared around the provision of information and advice: stakeholders perceived the current regime to be cumbersome, highly prescribed, and resulting in information overload; yet, through the narrow lens of 'information vulnerability', they could not conceive of alternatives that would provide better rather than simply more regulation.

\section{(5) Conclusions}

The Financial Services Act 2012 set out to pursue a more nuanced approach to the protection of financial services consumers. While information disclosure and professional advice has remained an important theme in consumer protection regulation, the re-constituted FCA has demonstrated that these techniques should be used in conjunction with other methods, including product and price regulation, where market conditions and risk to consumers renders this appropriate. For example, in January 2015 (FCA 2014), the FCA imposed a price cap on high cost, short term, credit (pay-day loans), in response to concerns about safety and affordability of transactions in this sector. The pay-day loans regime also applied a 
framework of rules to regulate responsible lending; to regulate product terms in the form of a rollover restriction and a price cap; and to apply an interventionist, rigorous and consumercentric supervision regime (Fejos, 2015). Reviewing the 'pay-day loans' price cap in 2017, the FCA also signalled concerns about other forms of high-cost, short-term credit, including unarranged overdrafts, and announced plans to consult on tailored solutions to address concerns in Spring 2018 (FCA, 2017b).

While the financial services regulator has long recognised that equity release is a high-risk sector (FSA, 2002), at $0.5 \%$ of the conventional mortgage market at the time of the Mortgage Market Review it was a relatively small market - although it is strategically important from a fiscal policy perspective (Overton \& Fox O’Mahony, 2015), and the impact of bad outcomes for older consumers is significant. Record growth in 2016 saw $£ 2.15$ billion released through 27,534 new transactions (Equity Release Council, 2017). When compared to FCA estimates of 400 firms serving high-cost short-term credit to 1.6 million customers, in 10 million loans at the point that product regulation was introduced in 2013 (CFA, 2015), there is clearly an issue of scale, although the high value of transactions relative to many other retail financial services means that suboptimal outcomes are potentially catastrophic for older consumers (FCA, 2017a). The relatively small scale of the market arguably explains why the FCA having recognised the nature and extent of situational vulnerability for older consumers - has fallen back on 'nudging' the sector towards better industry self-regulation of product terms and conditions (FCA, 2017a). Another explanation may be that the industry narrative that these are 'complex' products, and already 'over-regulated' may have discouraged direct intervention, despite the growing concerns surrounding ageing, borrowing and financial services expressed across the sector, by the regulator and by government.

Against this backdrop, our stakeholder findings raise a range of issues. Firstly, it is noteworthy that our findings revealed a clear consensus among equity release stakeholders that the current regulatory approach, combined with industry self-regulation - which adds requirements of mandatory legal advice and that products offer a 'no negative equity guarantee' - provides adequate protection for consumers. Secondly, this view was consistently rooted in stakeholders' perception of consumer vulnerability in terms of financial capability - without regard to situational pressures or need; which, in turn, underpinned a widespread - and firmly held - belief in the effectiveness of financial advice as the quintessential regulatory mechanism through which good consumer outcomes can be 
supported. Comparing these findings with insights from our earlier study of equity release consumers, we found that stakeholders' conceptions of consumer vulnerability were misaligned to the realities of consumer experiences - which indicated a much wider frame of triggers for consumer risk, including the pressures of releasing equity to address pressing financial difficulties, and the limited power of professional advice in enabling consumers experiencing situational pressures to make better decisions.

This misalignment raises important questions about the relationship between industry stakeholders' perceptions of consumer vulnerabilities in equity release transactions, on the one hand, and the realities of consumer experiences on the other. The narrow lens through which stakeholders perceived consumer experiences of vulnerability in this context, as well as their perception that equity release is already a highly-regulated market, appeared to constitute a barrier to stakeholders' conception of consumer protection strategies beyond the information and advice paradigm. Our consumer study findings suggested that additional measures, based in the recognition of situational vulnerabilities, could improve consumer outcomes in this sector. Such measures might include the regulation of product terms: for example, to overcome the current inflexibility around porting products from one property to another; and to address the costly early repayment charges and high interest rates which continue to have a disproportionate impact on consumers who are less well off, who may be entering into equity release to consolidate existing debt, and who are ill equipped to manage the adverse consequences of a sub-optimal decision.

The stakeholder findings suggest that if the FCA's 'nudge' approach is to be effective, the industry will need to adopt a broader conception of consumer vulnerability than has been evident to date. Reflecting on the FCA's conception of consumer vulnerability, one of our stakeholder participants commented that:

they still clearly don't understand equity release and where it fits, just labelling everybody as potentially vulnerable is not really so at all, yes, there's some vulnerable people as we discussed, but it's probably relatively low and the concentration will be the older end any way (Stakeholder 08)

While our consumer findings highlighted the importance of context - particularly financial 'dire straits' - in the consumer's transactional experience of advice; participants in our stakeholder study did not refer to contextual pressure when they talked about consumer 
vulnerability. Similarly, pressure of circumstances was not included in their accounts of the challenges, or possible solutions, for better (government or industry) regulation to improve consumer outcomes, particularly for less well-off consumers.

The Financial Services Act 2012, and the newly-constituted Financial Conduct Authority, promised a more nuanced approach to consumer protection, that recognised the significance of consumer context in determining the nature and extent of risk and so - looking beyond the information and advice paradigm - the nature of appropriate regulation in financial services transactions (Fox O'Mahony, Twigg-Flesner \& Akinbami, 2015). As the FCA looks to the equity release industry to craft its own responses to concerns about the vulnerability of its consumer population, our findings signal to a need for further brokerage work to ensure that aligned with the post-2012 FCA philosophy - industry stakeholders can effectively recalibrate their conceptions of equity release consumers, based on an outward-looking evaluation of the needs of an increasingly differentiated consumer population, with due regard to the FCA's post-crisis approach to regulation, and looking beyond information and advice to develop strategies that more effectively meet the needs of less well-off consumers.

\section{References}

Atkinson, A., McKay, S., Kempson, E. \& Collard, S. (2006). Levels of Financial Capability in the UK: Results of a Baseline Survey, London: FSA Consumer Research Paper No. 47

Best, A. (1981). When consumers complain. New York: Columbia University Press

Burns, F. (2012). The Evolving Statutory Regulation of Reverse Mortgages in Australia's Risk Society, Monash UL Rev., 39, 611 - 653

Cartwright, P. (2004). Banks, Consumers and Regulation. Oxford: Hart Publishing

Cartwright, P. (2015). Understanding and protecting vulnerable financial consumers, Journal of Consumer Policy, 38, 2,119-138.

CML (2015). Consumer Demand for Retirement Borrowing (A Report prepared for the CML by Louise Overton \& Lorna Fox O'Mahony), (November 2015), https://www.cml.org.uk/documents/research-report-on-consumer-demand-for-retirementborrowing/research-report-on-consumer-demand-for-retirement-borrowing.pdf

CML (2016a). Lifetime borrowing: a maturing market, https://www.cml.org.uk/news/newsand-views/lifetime-borrowing-a-maturing-market/ 
CML (2016b). Retirement Borrowing: Reality, Perceptions, Projections and Potential, https://www.cml.org.uk/news/press-releases/borrowing-in-retirement-cml-report-and-nextsteps/

CML (2017). Later Life Advice: New Mindset, Old Silos, https://www.cml.org.uk/news/cmlresearch/the-advice-framework-for-older-mortgage-customers-an-assessment/

Consumer Affairs Victoria. (2004). What do we mean by vulnerable and disadvantaged consumers? Melbourne: Consumer Affairs Victoria

CFA/SMF (2015). A Modern Credit Revolution: An Analysis of the Short-Term Credit Market, http://cfa-uk.co.uk/wp-content/uploads/2016/11/SMF-Report-AKT10796.pdf

Croucher, K.\& Rhodes,P. (2006). Testing Consumer Views on Paying for Long-Term Care, York: Joseph Rowntree Foundation

Ennew, C.T. \& Sekhon, H. (2007). "Measuring trust in financial services: the trust index", Consumer Policy Review, 17, 2, 62-68

ERC (Equity Release Council) (2017). Equity Release Market Report, Autumn 2017, http://www.equityreleasecouncil.com/document-library/equity-release-market-report-autumn$2017 /$

FCA (2014). Policy Statement PS14/16 - Detailed rules for the price cap on high-cost shortterm credit, November 2014, London: FCA

FCA (2015). Consumer vulnerability. FCA Occasional Paper No. 8. London: Financial Conduct Authority

FCA (2016). Aging Population and Financial Services. A Collection of Perspectives. DP16/1 https://www.fca.org.uk/publication/discussion/dp16-01.pdf

FCA (2017a). 'Ageing population and financial services' (Occasional Paper 31), London: FCA, September 2017; https://www.fca.org.uk/publications/occasional-papers/ageingpopulation-financial-services

FCA (2017b). 'Financial Conduct Authority sets out agenda and priorities for consumer credit' (Press Release, published 31/07/2017); https://www.fca.org.uk/news/pressreleases/agenda-priorities-consumer-credit

Fejos, A. (2015). 'Achieving Safety and Affordability in the UK Payday Loans Market' Journal of Consumer Policy 38, 2, 181-202

Fox O’Mahony, L. (2012). Home Equity and Older Owners: Between Risk and Regulation, Oxford: Hart Publishing

Fox O’Mahony, L. \& Overton, L (2014). Financial advice, differentiated consumers and the regulation of equity release transactions, Journal of Law and Society, 41, 3, 446-469 
Fox O'Mahony, L. \& Overton, L. (2015). Asset-based welfare, equity release and the meaning of the owned home, Housing Studies, 30, 3, 392-412.

Fox O'Mahony, L., Twigg-Flesner, C., \& Akinbami, F (2015). Conceptualising the Consumer of Financial Services: a New Approach? Journal of Consumer Policy, 38, 2, 111117

FSA (2002). The FSA's approach to regulating mortgage sales ,Consultation Paper 146, London: FSA

FSA (2007). Mortgage Effectiveness Review: focusing on higher risk areas, FSA/PN/04, http://fsa.gov.uk/pages/Library/Communication/PR/2007/047.shtml

FSA (2008). Mortgage effectiveness review, Stage 2 Report, London: FSA http://www.fsa.gov.uk/pubs/other/MER2_report.pdf

FSA (2011a). The financial conduct authority: Approach to regulation. London: Financial Services Authority

FSA (2011b). Mortgage Market Review: Proposed Package of Reforms, CP11/31 www.fsa.gov.uk/library/policy/cp/2011/11_31.shtml

George, M., \& Lennard, L. (2007). At a disadvantage, Consumer Policy Review, 17, 2, 56-61

HM Treasury (2000). Competition in UK Banking: A Report to the Chancellor of the Exchequer, London: TSO

HM Treasury (2008). Thoresen Review of Generic Financial Advice: Final Report, London: HM Treasury

HM Treasury (2011). A new approach to financial regulation: building a stronger system, London: HM Treasury

House of Lords Select Committee on Public Service and Demographic Change (2013). Ready for Ageing? London: The Stationary Office

Howells, G. (2005). The Potential and Limits of Consumer Empowerment by Information, Journal of Law and Society, 32, 349 -357.

Key Retirement Solutions (2017). Market Monitor, Half year 2017, https://www.keyretirement.co.uk/MediaLibrary/KeyRetirement/images/Market-Monitor-HY2017-FINAL.PDF

Leonard, P. (1997). Postmodern Welfare: Reconstructing an Emancipatory Project, London: Sage.

MCOB (2004). FSA Handbook, Mortgages and Home Finance: Conduct of Business Sourcebook 
OFT (1999). Vulnerable Consumers and Financial Services: The Report of the Director General's Inquiry, London: OFT

Overton, L. \& Fox O’Mahony, L. (2015). Consumer Demand for Retirement Borrowing, London: Council for Mortgage Lenders

Overton, L. \& Fox O’Mahony, L. (2017) Understanding Attitudes to Paying for Care amongst Equity Release Consumers: citizenship, solidarity and the 'hardworking homeowner', Journal of Social Policy, 46, 1, 49-67

Pagliari, S. (ed.). (2012). Making good financial regulation: towards a policy response to regulatory capture. Grosvenor House Publishing, London, UK

Price. D. \& Livsey, L. (2013). 'Financing later life: pensions, care, housing equity and the new politics of old age' in G. Ramia., K. Farnsworth and Z. Irwin (eds.) Social Policy Review 25, Bristol: Policy Press

Ringold, D. J. (1995). 'Social criticisms of target marketing: Process or product'. American Behavioural Scientist, 38, 578-592

Rowlingson, K. (2006). 'Living poor to die rich'? or 'spending the kids' inheritance? Attitudes to assets and inheritance in later life, Journal of Social Policy, 35, 2, 175-192.

Smith, N.C. \& E. Cooper-Martin (1997). Ethics and Target Marketing: The Role of Product Harm and Consumer Vulnerability. Journal of Marketing, 61, 3, 1-20

Spencer, L., Ritchie, J. \& O'Connor, W. (2003). 'Carrying out Qualitative Analysis' in J. Ritchie and J. Lewis (eds.) Qualitative Research Practice, London: Sage, pp. 219-262

Stearn, J. (2012). Tackling consumer vulnerability: An action plan for empowerment. London: Consumer Focus

Stigler, G. (1971). 'The theory of economic regulation', Bell Journal of Economics and Management Science 2 (spring): 3-21.

Toussaint, J. \& Elsinga, M. (2009). Exploring 'housing asset-based welfare': Can the UK be held up as an example for Europe? Housing Studies, 24, 5, 669-692

Wilhelmsson, T. (1997). 'Consumer law and social justice' in I. Ramsey (ed.) Consumer Law in the Global Economy, Aldershot: Ashgate 